\title{
Lost on the Way: Nonresponse and its Influence on Turnout Bias in Postelection Surveys
}

\section{Pascal Sciarini and Andreas C. Goldberg}

Department of Political Science and International Relations, University of Geneva, Switzerland All correspondence concerning this article should be addressed to Pascal Sciarini, Department of Political Science and International Relations, University of Geneva, 40 Bd du Pont-d'Arve CH-ı2 I Genève 4, Switzerland. E-mail: Pascal.Sciarini@unige.ch

\begin{abstract}
Earlier studies on turnout bias in postelection surveys have focused on vote overreporting (measurement bias) and have disregarded nonresponse bias associated with voter overrepresentation. Based on a unique data set of validated votes collected for two different ballots, we offer an in-depth analysis of the size and sources of nonresponse bias. On the aggregate level, we find that voter overrepresentation accounts for a larger share of total turnout bias than misreporting. On the individual level, past voting record, ballot vote, and age appear as strong predictors of survey participation. Breaking down further the analysis, we show that these factors contribute to nonresponse bias through both contact and cooperation. By contrast, the effects of some other factors work at cross-purpose in the contact and cooperation stages.
\end{abstract}

Overestimation of turnout is a classic flaw in postelection surveys. It has a double cause: Voter overrepresentation among survey respondents (nonresponse bias), and misreporting of respondents claiming that they voted whereas they did not (measurement bias). ${ }^{1}$ In the late r98os, the American National Election Studies (ANES) directors decided to abandon the vote validation procedure, that is, the matching of self-reported turnout with official records, arguing that government record checks contained so many errors that they were not more valid than the self-reports of survey respondents (Berent, Krosnick, \& Lupia, 20II). They reaffirm this view in a recent report based on the 2008 ANES turnout validation exercise, and claim that the upward trend in turnout bias in ANES does not stem from lying or memory failure, but from the increased overrepresentation of

\footnotetext{
${ }^{1}$ The concepts of "nonresponse bias" and "measurement error" are central to survey participation literature, whereas vote validation studies use the more specific concepts of "overrepresentation of voters" and "misreporting" (or "overreporting"). In this article, we use both interchangeably.
} 
actual voters among survey respondents (Berent et al., 20 I , see also Burden 2000, p. 389).

This view is, however, not dominant. According to a competing and widespread conception, turnout bias is primarily a function of vote overreporting and only secondarily a function of voter overrepresentation (e.g., Ansolabehere \& Hersh, 2012; Deufel \& Kedar, 2010). The extensive-mainly U.S.-literature has advanced our understanding of overreporting (Belli, Traugott, \& Beckman, 200I; Bernstein, Chadha, \& Montjoy, 200I; Cassel, 2003; Deufel \& Kedar, 20ıо; Katz \& Katz, 20ıо; Presser \& Traugott, I992; Sigelman, I982; Silver, Anderson, \& Abramson, I986). However, we still know little about the size and determinants of voter overrepresentation.

Admittedly, the analysis of voter overrepresentation requires reliable information about the validated votes of both citizens who were interviewed and who were not. This condition is rarely fulfilled. Existing vote validation studies focus on survey respondents, but do not validate the votes of nonrespondents. Given that both voter overrepresentation and vote overreporting contribute to the overestimation of turnout in surveys, focusing on misreporting and ignoring nonresponse obviously misses an important component of the analysis of turnout bias. ${ }^{2}$

Against this background, the purpose of this article is to offer an in-depth analysis of the size and sources of nonresponse bias. To that end, we use a unique data set collected on two distinct elections, which provides highly reliable information on validated turnout of both survey respondents and nonrespondents. This enables us to separate nonresponse bias from vote measurement error and to evaluate how they each account to total turnout bias. The data set also allows for a fine-grained analysis of the two constitutive elements of survey participation, namely contact and cooperation. Moreover, we take advantage of the strong differences in response rate existing between the two surveys to explore in how far these differences matter for turnout bias. Finally, to our knowledge our Swiss study is one of the few that analyzes turnout bias outside the United States, which will help us to evaluate whether and to what extent our results conform to- or contrast with—existing findings.

\section{Theory}

\section{Survey Participation, Nonresponse Bias, and Total Turnout Bias}

Overestimation of turnout in surveys results from both nonresponse bias (voter overrepresentation) and measurement bias (vote overreporting).

\footnotetext{
${ }^{2}$ In a companion paper, we take a closer look at the relationship between voter overrepresentation and vote overreporting. To that end, we apply a Heckman selection model in which the outcome equation estimates the probability of overreporting conditional on the probability of participation in the survey (Sciarini \& Goldberg, forthcoming).
} 
According to a widespread view, measurement error accounts for the bulk of total turnout bias (e.g., Ansolabehere \& Hersh, 20I2; Deufel \& Kedar, 2010). In Ansolabehere and Hersh's (2012) data from the Cooperative Congressional Election Study (CCES), overreporting accounts for roughly two thirds of total turnout bias, and voter overrepresentation for only one third. The respective share of voter overrepresentation and vote overreporting is more balanced in the ANES data, where in some years nonresponse contributed to half of total turnout bias_or even more (Burden, 2000; Deufel \& Kedar, 20I0, p. 294). Differences in sampling design may account for the varying share of nonresponse and measurement biases between CCES and ANES data. ${ }^{3}$ However, the nonresponse bias is sizeable in both cases and, therefore, deserves a closer look.

Differences in citizens' propensity to participate in a survey, which result in nonresponse bias, may have various reasons. In general, participation in a survey is a function of accessibility to be contacted, and of the ability and willingness of contacted persons to cooperate (Goyder, I987; Groves, Cialdini, \& Couper, I992; Groves \& Mathiowetz, I984; Quinn, Gutek, \& Walsh, I980; Smith, I983; Stoop, 2005). On the one hand, the determinants of accessibility and ability to participate in a survey are fairly well-known. Different survey modes such as face-to-face and telephone surveys share some commonalities in that respect, in particular with regard to the effects of age, civil status, or professional status. Young persons, working people, and singles who are rarely at home are harder to contact than married people and the elderly. While age generally has a positive influence on the likelihood of contact, empirical records show that beyond a certain age threshold, health problems and social isolation decrease the ability to respond to surveys. Online surveys, for their part, face specific problems of coverage, such as the underrepresentation of older people and of people without Internet access (e.g., Atkeson, Adams, \& Alvarez, 20I4).

On the other hand, contacted persons' millingness to participate in a survey and answer questions of interest is likely to vary across surveys, for example, depending on the survey topic. Groves (2006; also Groves \& Peytcheva, 2008) has put forward several models relating the likelihood that members of a sample will participate in a survey to the probability that they will answer survey questions. According to the "common cause model," the same causal factors may influence both survey participation and the response to some survey variables, thus generating a covariance between the two attributes. Groves, Singer, \& Corning's (2000) leverage-salience theory further helps to specify the conditions under which variations in response propensity tend to result in nonresponse bias (see also Groves \& Peytcheva, 2008; Groves,

\footnotetext{
${ }^{3}$ Most noticeably, the ANES is a probability sample, whereas the CCES is an opt-in, nonprobability sample. Nonprobability samples notoriously overrepresent politically engaged persons (e.g., Chang \& Krosnick, 2009; Yeager et al., 20II).
} 
Presser, \& Dipko, 2004). This theory states that a given survey attribute (e.g., its topic) has different "leverages" on the survey participation decision, depending on the importance that the sampled people assign to the attribute. Whether or not the attribute is made salient to the sampled person (e.g., at the start of the interview) will further influence the activation of the potential leverage.

When a factor with great leverage on the survey participation decision is also an item of survey measurement, survey statistics based on that factor are likely to have a large nonresponse bias. Applying the leverage-salience argument to the topic of our study, it is safe to argue that participation in a postelection survey has a (far) greater leverage among voters than nonvoters. As Brehm (1993, p. 70) puts it, participation in a survey about politics and political participation are two sides of the same coin, meaning that people who vote more are also more likely to participate in surveys about politics.

Socio-demographic characteristics that relate to political participation are also likely to influence willingness to respond to a postelection survey. Age is again one of these factors. Political interest and information, as well as social integration, increase with age, which leads to higher political involvement (e.g., Riley, Foner \& Waring, I988) and, arguably, higher survey participation. A similar reasoning applies to another factor relating to social integration, namely, residence duration (e.g., Cassel \& Hill, I98I; Squire, Wolfinger, \& Glass, I987). Citizens who have lived in the same place for a long time care more about (local) politics and are, therefore, more likely to participate both in politics and in surveys about politics. In summary, we assume that participation in postelection surveys is higher among voters, middle-aged people, married persons, and long-term residents.

\section{Response Rate, Nonresponse Bias, and Measurement Error}

According to the "continuum of resistance," the likelihood of having nonvoters in a survey increases with a higher response rate (Burden, 2000). Given that nonvoters are usually reluctant to participate in political surveys, increasing the response rate should help to increase the share of nonvoters in the realized sample and, therefore, to reduce voter overrepresentation. Some scholars have, however, questioned the "continuum of resistance." They argue that increasing the response rate is likely to increase the share of nonvoters only if the response rate approaches $100 \%$. Below that percentage, increasing response rate may in fact have the reverse effect, namely, to bring an even more disproportionate share of active voters in the sample (Lin \& Schaeffer, I995; Selb \& Munzert, 20I3). Empirically, findings from survey research in various fields suggest that a low response rate does not necessarily lead to higher nonresponse bias (e.g., Curtin, Presser, \& Singer, 2000; Groves et al., 2004; Groves, 2006; Groves \& Peytcheva, 2008). 
Olson (2006) has extended the "common cause model" to relationships between response rate and measurement error. She argues that the same factors that influence the propensity to participate in a survey may also influence the propensity to respond inaccurately to survey questions. As a result, efforts to increase response rate may come at the price of increasing measurement errors, as more citizens with something embarrassing to report will be included in the survey. In the present context, increasing the response rate may reduce voter overrepresentation, and yet, it may also increase the number of embarrassed nonvoters prone to overreport among survey respondents (Selb \& Munzert, 20ı3; Tourangeau \& Yan, 2007; Tourangeau, Groves, \& Redline, 20I0). The comparison of two surveys with different response rates will help to check whether these expectations hold.

\section{Data}

Having recorded values available for estimating nonresponse bias is rare (Olson, 2006, p. 752). This holds all the more true for turnout data. In that sense, our two data sets are exceptionally rich. They include validated turnout data for the whole sample, that is, for both survey respondents and nonrespondents. The data sets were both collected in the canton of Geneva, Switzerland, the first in the context of the October 20I I national elections and the second in the following year in the aftermath of a compulsory referendum on the new cantonal Constitution. In both cases, the cantonal administration drew a random sample of Geneva's citizens from the official vote registry. This served as the basis for a telephone survey carried out by a survey company. The initial sample comprised I,500 individuals in the first survey and 2,500 in the second. In Switzerland, citizens do not need to register to vote. Therefore, the official vote registry includes all eligible voters.

After the survey fieldwork was completed, the resulting file was sent to the cantonal administration that added the information regarding actual turnout. ${ }^{4}$ While most validation studies use official records to ex post verify self-reported votes, which is error-prone (Berent et al., 201 I) ${ }^{5}$ our validated data are highly reliable. To the extent that the official register was used as the sampling frame from the start, no matching was required. In addition, vote validation was easy and virtually error-free, as it occurred through an electronic reading of the voting card that each voter had to sign and send back by postal mail or put in the ballot box on Election Day. The files comprising information about both

\footnotetext{
${ }^{4}$ We thank the Service of Votes and Elections (SVE) and the Statistical Cantonal Office (OCSTAT) for providing us with the validated turnout data.

${ }^{5}$ According to Berent et al.'s (20II) analysis of several large American states, official government records of registration and turnout contain numerous errors with strong variations across states. Common means of validation underestimate registration and turnout rates because they fail to locate records for respondents who were classified as not registered when they were registered.
} 
reported and actual turnout at the $20 \mathrm{II}$ national election and the 2012 referendum, respectively, were then de-identified (anonymized) and sent to us. ${ }^{6}$

For each person included in the initial sample, we do not only have information regarding whether she participated in the current vote. We also have information about her actual vote (or abstention) in all previous ballots held in the canton of Geneva between I996 and 20I I-20I2, that is, roughly 80 referendums or elections at the national or local level (Sciarini, Cappelletti, Goldberg, \& Lanz, forthcoming; Tawfik, Sciarini, \& Horber, 2012). More specifically, a citizen's past voting record is measured as the share of ballots (elections and referendums) in which she participated, out of the maximum number of ballots in which she could participate. ${ }^{7}$

The data set also provides information about individuals' key socio-demographic characteristics, namely, age, sex, marital status, and residence duration. Given that age does presumably not have a linear effect, we include age as a simple, square, and cubic term. Marital status distinguishes between singles (ref. category), married, and divorced/widowed persons. Finally, residence duration distinguishes citizens living in Geneva for less or more than ro years.

Furthermore, the data set also informs about the reasons why a person did not respond to the survey. These reasons were recoded into the two main components of nonresponse, that is, contact and cooperation. We further divided noncontacts into two sub-categories, by distinguishing people for whom we could not find any phone number, from people whom we could not reach. Similarly, we specified the reasons for noncooperation by distinguishing "inability" from "unwillingness" (see Table A I).

\section{Contact, Cooperation, and Nonresponse Rate}

While both surveys are based on the same sampling procedure, they differ from one another in terms of sponsorship, level of effort to reduce nonresponse, and interview duration. First, while both surveys were announced in advance with a letter sent to all sampled citizens, the sponsor was different. The 20 I I survey took place in parallel to the Swiss national election study. The announcement letter was sent by the University of Lausanne, which hosts the Swiss election studies. By contrast, the 2012 survey was sponsored by the Geneva state government. According to prior studies, government sponsored surveys achieve higher response rates by increasing the commitment felt by sampled persons

\footnotetext{
${ }^{6}$ The wording of the turnout question asked in both surveys was as follows: "In general, when there is an election or a direct democratic vote in Switzerland, more than half of citizens do not vote. Last Sunday there was an election/a direct democratic vote. Did you participate in that vote?"

${ }^{7}$ Taking the example of the 20 I I survey, for a person residing in Geneva since 1996 the maximal number of ballots equates to the total number of ballots held between I996 and 201 I, namely 79. For a younger person who got his/her voting rights after 1996, or for a person who arrived in Geneva after I996, the maximal number of ballots is of course lower than 79 .
} 
(De Leeuw \& de Heer, 2002; Groves \& Peytcheva, 2008). Second, the survey company was not the same in both surveys. The company that conducted the 2012 survey made a stronger effort to reduce nonresponse, with measures that aimed to increase contact rate. Sampled citizens for whom we did not find any telephone number benefited from special treatment. Instead of the standard letter announcing the forthcoming survey, these persons received a letter asking for their phone number. Two weeks later, the persons who did not respond received a second letter offering two possibilities. They could either call a hotline to set up an appointment (or do the interview straight away) or fill the questionnaire online through the Internet. The same possibilities were offered to sampled citizens with a phone number but with whom no contact could be established during the first io days of fieldwork.

Third, the 20I I survey was highly demanding, as it rested on a long questionnaire. During the introduction, interviewers announced the estimated interview length, $25 \mathrm{~min}$ in the 20 I s survey and between Io and I $5 \mathrm{~min}$ in the 2012 survey. According to past research, increasing the announced interview time reduces response rate in both telephone and web surveys (Galesic \& Bosnjack, 2009; Marcus, Bosnjak, Lindner, Pilischenko, \& Schuetz, 2007; Roberts, Eva, Allum, \& Lynn, 20I0). Therefore, the far longer duration of the 20I I survey was likely to have detrimental consequences for the propensity to cooperate.

All mentioned differences arguably account for the sharp difference in response rate between the two surveys (Table I). From the initial sample of I, 500 persons drawn for the 20 I I survey, 8I o persons could be contacted and 392 were able and willing to participate in the survey, which results in an AAPOR RRI of $26.3 \%$. The response rate is thus low, but not unusual for postelection surveys, which commonly display lower response rates than other surveys (Groves \& Peytcheva, 2008). The response rate was almost twice as high in our second survey. Of the 2,500 persons included in the initial sample, I,780 could be contacted and I,23I could be interviewed ( 1,067 by phone and I64 by self-administration through the Internet). The AAPOR RRI thus amounts to $49.2 \%$. We can see from Table $\mathrm{I}$ that the higher response rate reached in the second survey is a result of both higher contact rate and-even more so-higher cooperation rate. Cooperation is measured and analyzed conditional on successful contact.

While our data set offers full coverage of the voting-eligible population, it does not escape the main source of slippage in a register-based sampling process, namely, incomplete matching between addresses and phone numbers (Green \& Gerber, 2006). In both surveys, we were unable to obtain phone numbers for about $20 \%$ of the initial sample. However, our data allow us to identify citizens with unknown phone numbers, and to check whether they have a distinct socio-demographic profile. We come back to that issue toward the end of the empirical section. 
Table I

Response Rate, Contact Rate, and Cooperation Rate

\begin{tabular}{lllllll}
\hline Year & $\begin{array}{l}\text { Initial } \\
\text { sample }\end{array}$ & Contacts & $\begin{array}{l}\text { Contact rate } \\
(\%)\end{array}$ & Interviews & $\begin{array}{l}\text { Cooperation rate } \\
(\%)\end{array}$ & $\begin{array}{l}\text { Response rate } \\
(\text { AAPOR RI }) \\
(\%)\end{array}$ \\
\hline 201 I & I,500 & 804 & 53.6 & 392 & 48.8 & 26.3 \\
2012 & 2,500 & I,754 & 70.2 & I,23I & 70.2 & 49.2 \\
\hline
\end{tabular}

Note that the two surveys differ in an additional way. The 20I I survey related to national elections and the 2012 to a cantonal referendum. However, the differences in institutional ballot type are unlikely to matter in the present case. While national elections are of utmost importance in most countries, this does not hold to the same extent in Switzerland (Bochsler \& Wasserfallen, 20I3; Franklin, 2004). On the one hand, in the Swiss consensus democracy where the executive power is shared by the main political parties, national parliamentary elections do hardly have any influence on the composition of the national government. On the other hand, as a result of the strong development of direct legislation, elections compete with direct democratic votes. This, in turn, contributes to citizens' "participatory fatigue" and accounts for Switzerland's low turnout in comparative perspective (Franklin, 2004; Lutz \& Selb, 2007). At the 20I I national elections, turnout amounted to $44.8 \%$ in the Geneva district. The turnout rate regarding the cantonal referendum of October 2012 was even lower $(32.5 \%){ }^{8}$

\section{Results}

\section{Nonresponse Bias, Measurement Bias, and Total Turnout Bias}

Figure I presents the size of total turnout bias in the two surveys and shows how much nonresponse bias and measurement bias contribute to that total. The total turnout bias is measured by the difference between reported turnout among survey respondents and validated turnout in the initial sample. It amounts to 22.8 percentage points in the first survey and to I9.4 percentage points in the second. This is a rather high bias from a comparative perspective. In Selb and Munzert's (2013) collection of I28 postelection studies the average difference between sample and official turnouts is $\mathrm{I} 4$ percentage points. However, their collection includes several elections with high turnout

\footnotetext{
${ }^{8}$ The especially low turnout rate of the cantonal referendum was not because of the weak importance of the ballot at stake. Quite to the contrary, the replacement of the-more than a century-old cantonal constitution was a major political event. The direct democratic vote was supposed to be the coronation of a long decision-making process that lasted more than 3 years. However, only some small parties and organizations of the far right and far left opposed the new constitution, which arguably accounts for the low mobilization of voters.
} 
Figure I

Total turnout bias decomposed.
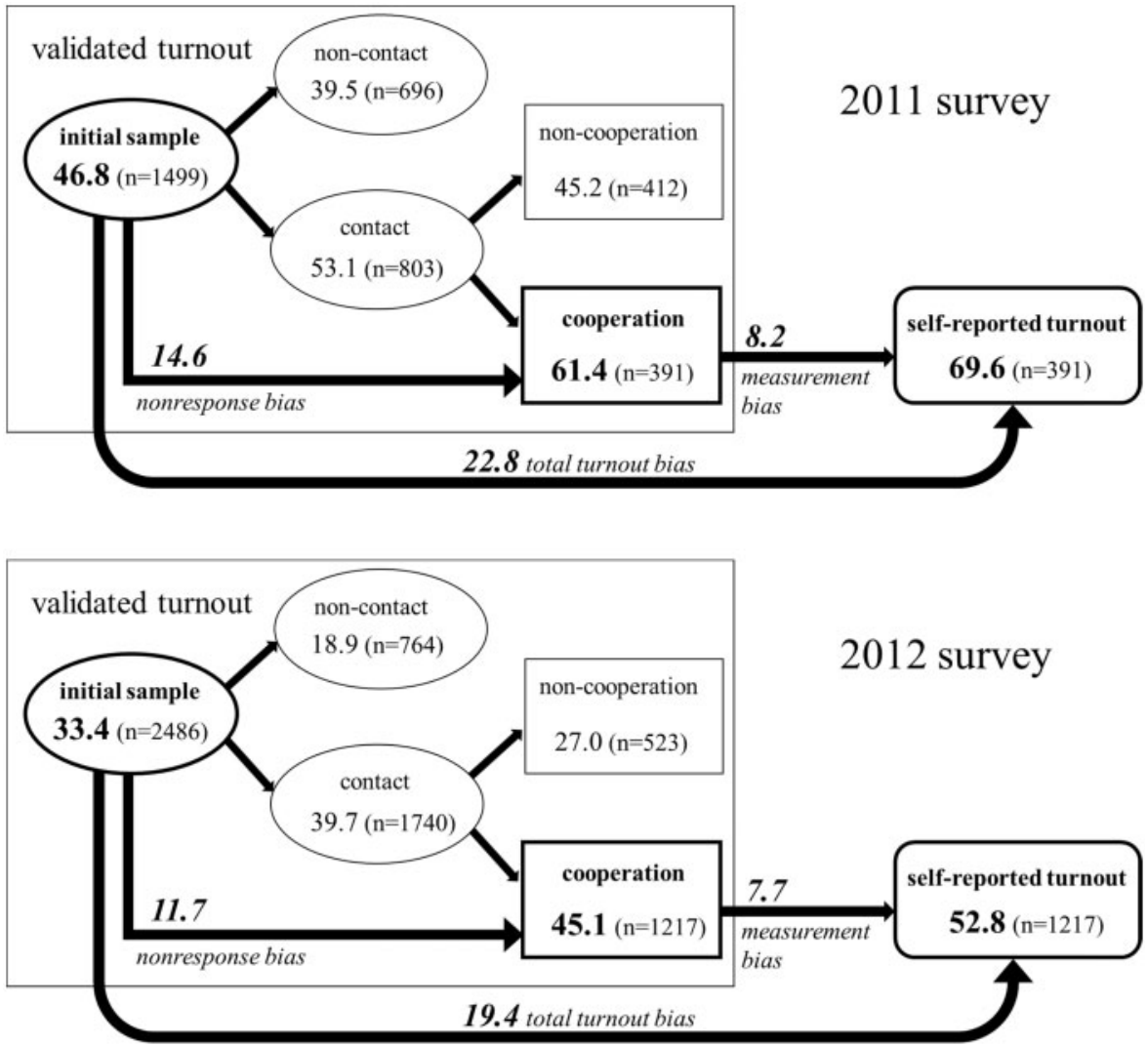

Note. Numbers in the text boxes represent the validated turnout per category and self-reported turnout, respectively. Numbers related to the arrows show the total and nonresponse/measurement bias. This figure excludes respondents who did not answer the turnout question (I person in $20 \mathrm{II}$ and I4 persons in 20I2)

rates. In such cases, a sort of "ceiling effect" occurs and necessarily limits the size of possible turnout bias. Such a "ceiling effect" does not hold in a low turnout country such as Switzerland-or the United States. The size of the total turnout bias in our two surveys is close to that observed in presidential elections in the United States (Burden, 2000; Deufel \& Kedar, 2010; McDonald, 2003).

The difference between validated turnout in the initial sample and validated turnout among cooperative persons (survey respondents) informs about nonresponse bias, that is, the bias induced by overrepresentation of actual voters in the realized sample (Figure I). In both studies, the nonresponse bias is sizeable. It accounts for $64 \%$ of total turnout bias in 
20 I I (14.6/22.8) and for $60 \%$ in 2012 (II.7/I9.4). The size of measurement bias (vote overreporting) is calculated as the difference between the validated and reported turnout among survey respondents. ${ }^{9}$ Vote misreporting accounts for $36 \%(8.2 / 22.8)$ of total bias in the first survey and $40 \%(7.7 / 19.4)$ in the second. Therefore, in our Swiss data, total turnout bias is primarily a function of the overrepresentation of politically active citizens among survey respondents, and only secondarily a function of vote overreporting. ${ }^{10}$

While nonresponse bias is large in both surveys, it is especially large in the survey with lower response rate. In addition, in our data a higher response rate does not go along with a higher measurement error. Despite the fact that the response rate is almost two times higher in the 2012 survey, the absolute level of overreporting is slightly lower than in the 20 I I survey (7.7 vs. 8.2). The difference in overreporting bias between both surveys is even larger if calculated in relative terms, that is, as the share of respondents who overreported out of the group of nonvoters among survey respondents. The relative share of overreporting is $2 \mathrm{I} \%$ in the $20 \mathrm{I}$ I survey $(8.2 / 38.6)$ and $\mathrm{I} 4 \%$ in the $20 \mathrm{I} 2$ survey $(7.7 / 54.9)$. These results run against the argument of the extended common cause model (Olson, 2006) that increasing the response rate attracts more embarrassed nonvoters into the sample and increases measurement error.

Table A2 shows that the possibility to fill the questionnaire online contributed to the smaller nonresponse bias and, even more so, to the smaller measurement error of the 2012 survey. This confirms Voogt and Saris' (2005) results that a mixed survey mode helps to decrease bias in the data. Further, Table $A_{3}$ indicates that in both surveys the nonresponse bias is especially large during the first week of interviews and much lower afterward. This means that the survey company is most likely to interview an overproportional share of voters during the first days of fieldwork.

Figure I offers even more detailed results regarding validated turnout by showing the respective values separately for the contact and cooperation stages. In both surveys, the validated turnout is much smaller among noncontacts than among contacted people. The same holds for noncooperative people, who show a lower validated turnout than cooperative persons, that is, survey respondents. The respective shares of contact and cooperation for the nonresponse bias are almost equally big, with a slightly higher share owing to contact in $20 \mathrm{I} 2$ and a slightly higher share owing to cooperation in $20 \mathrm{II}$.

\footnotetext{
${ }^{9}$ As is often the case, the share of voters who underreport, saying they abstained whereas they participated, is very low (roughly $\mathrm{I} \%$ of the realized sample).

${ }^{10}$ The distribution of nonresponse and overreporting in our Swiss data is closer to that in the ANES than in the CCES. Unlike the CCES, both the ANES and our Swiss surveys are based on probability samples. This may account for the fairly similar distribution of nonresponse and overreporting.
} 


\section{Survey Participation and Voter Overrepresentation}

The large size of nonresponse bias in our data calls for a more detailed examination of the factors leading to nonresponse. To that end, we turn to an individual-level analysis. As already mentioned, on the individual level, survey participation depends first on the possibility to establish a contact with a sampled person, and second on the willingness and ability of that person to cooperate and respond to survey questions. Accordingly, we start with the analysis of survey participation (Table 2, Model I), and then study its two components separately (contact in Model 2 and, for contacted persons, cooperation in Model 3).

Given that in each model the dependent variable is binary, we rely on probit regressions. The three models allow us to assess which variables play a role for survey participation in general and more specifically at which stage of the survey process. Such information is important, as it may help survey researchers to identify specific socio-demographic groups with a contact or cooperation problem and, therefore, to implement corrective measures that will decrease nonresponse bias. Moreover, comparing the coefficients between both surveys will also give us a hint whether differences in response rate result in different determinants of survey participation.

As expected, being married and being an active voter increases the probability of survey participation (model I). In the 2012 survey, both variables measuring past voting record and participation in the current vote have a significant effect. In the 20I I survey, the coefficient for participation in the current vote does not reach statistical significance. However, an additional analysis, not reported here, shows that this coefficient gets significant if we exclude the past voting record from the model. Thus, our results are in line with the claim of leverage-salience theory (Groves et al., 2000) that participation in a survey has a greater leverage among people interested in the survey topic, in the present case (frequent) voters. More specifically, they confirm that there is a strong relationship between political participation and participation in a survey about politics (Brehm, 1993). While this relationship is often assumed, it has rarely been tested for reasons of data unavailability.

Age also has a significant effect on survey participation, but this effect is difficult to grasp based on coefficients. Therefore, we plot the predicted probabilities (and related 95\% confidence intervals) of survey participation by age in Figure 2. Both graphs show an overall declining trend but with marked differences between the two surveys. Young persons have a probability of around $60 \%$ to take part in the survey. In the 2012 survey, this probability remains fairly stable for people up to 70 years, before falling abruptly afterward. In 20I I, in contrast, the youngest people are a kind of positive outlier. The probability of interview decreases sharply from people aged 20 to people aged 35 years, and then stabilizes until the age of 70 , however at a much lower 


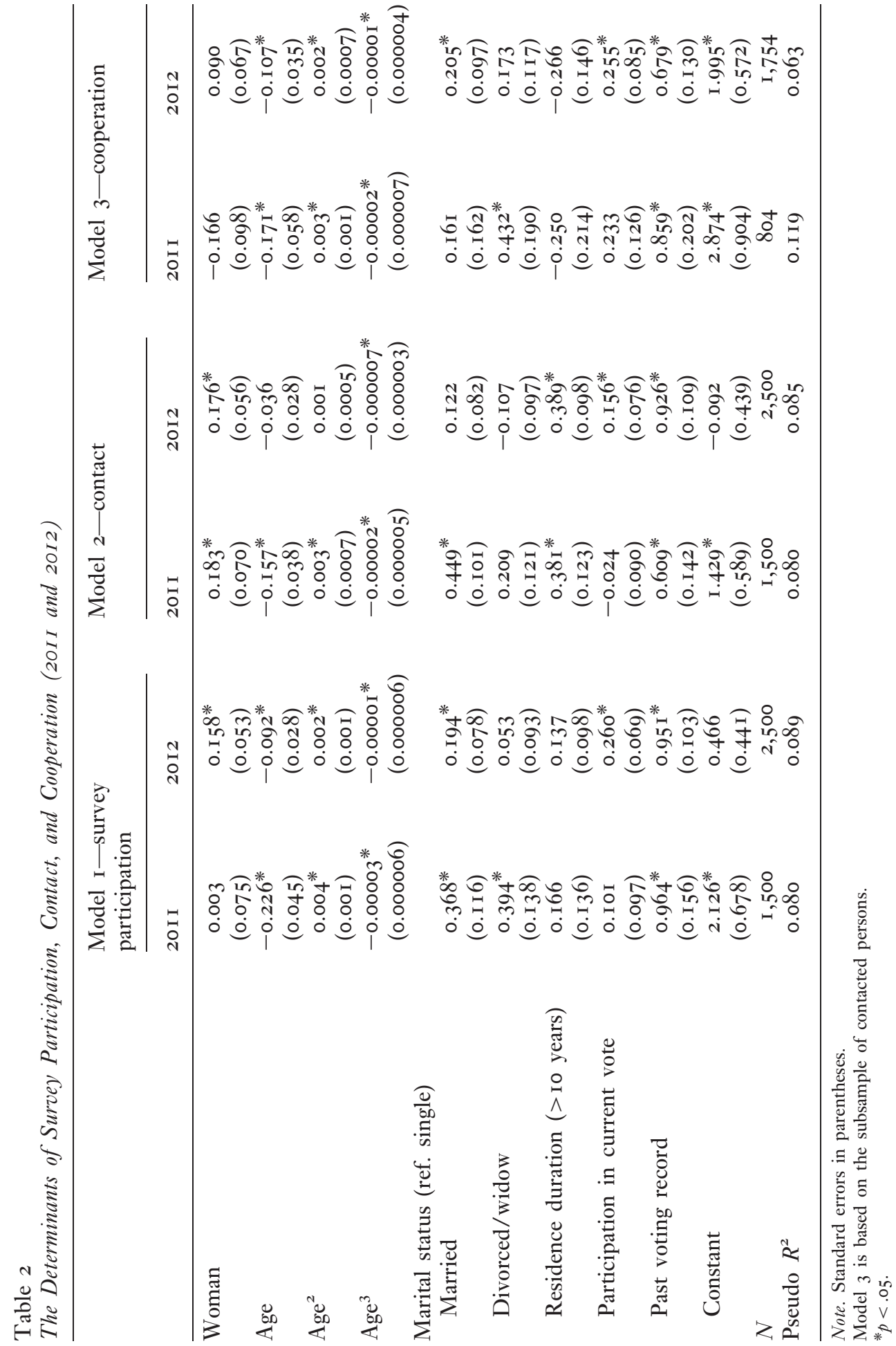


Figure 2

Predicted probability of survey participation by age
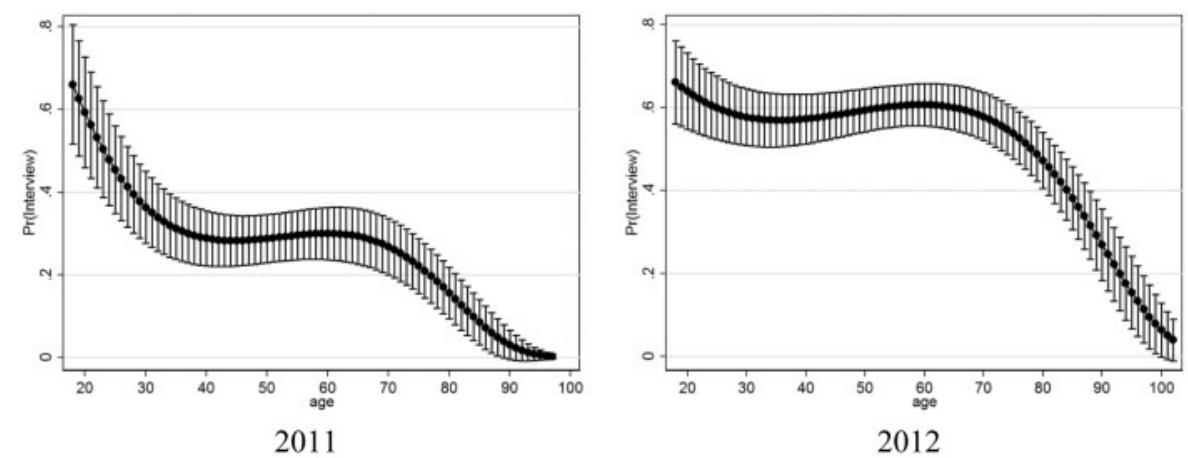

level than in the 2012 survey. A second downward trend again occurs among people over 70 years. In sum, our results do not confirm our expectation that response propensity would peak among middle-aged people. In our data, the likelihood of survey participation peaks among the youngest citizens, especially in the 20I I survey.

The results regarding residence duration also run against our expectations, as in both surveys, this variable has no significant influence on survey participation. Finally, the effects of gender and being divorced/widowed differ between the two surveys. In the 2012 survey, women have a higher likelihood of survey participation than men. In the 20I I survey, participation is more likely among divorced/widowed people than among singles (reference category).

The separate models for contact and cooperation in Models 2 and 3 provide a finer-grained view of the sources of nonresponse and help to test whether and to what extent the effects of contact and cooperation add up and jointly contribute to survey participation or, to the contrary, whether these effects cancel each other out. The latter would hold if, for example, a given variable has a positive influence on the likelihood of contact, but a negative influence on the likelihood of cooperation.

Three variables, namely age, past voting record, and participation in the current vote have consistent effects on contact and cooperation. Figure 3 shows the predicted probabilities of contact by age. In 20II, the curve has a $\mathrm{u}$-shaped form among young and middle-aged people, and then turns into an inverted u-shape among older people. It is especially the group of people aged 30-50 that displays a low odds of contact. The curvilinear form is far less marked in the 2012 survey with a higher response rate. Here, the likelihood of contact is fairly stable from people aged $20-75$, and declines only among the 
Figure 3

Predicted probability of contact by age
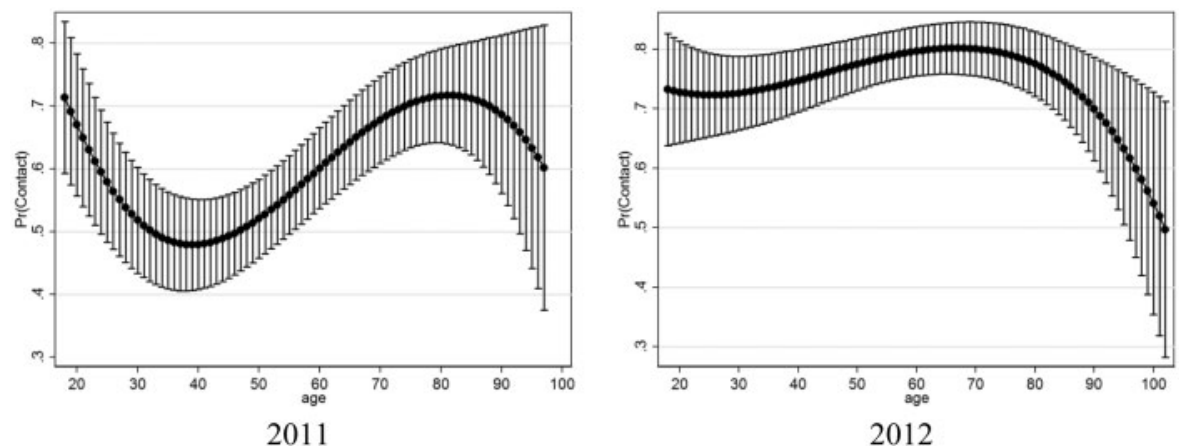

oldest citizens. The higher level of efforts made in that second survey presumably accounts for the more stable contact pattern across age. ${ }^{11}$

At a first glance, the result that contact decreases with age does not conform to that of U.S. studies. There, it has been found that young people participate less politically — and are harder to survey — as a result of their higher residential mobility and of the residential-based registration system (Ansolabehere, Hersh, \& Shepsle, 2012, pp. 336-337). However, in Switzerland, citizens do not need to register to vote and mobility is not as high as in the United States. Young people aged I 8-25 are likely to still live with their parents and, therefore, to be more easily reachable for an interview than the subsequent age-groups.

In both surveys, age has also a strong effect on cooperation (Model 3). As the predicted probabilities to cooperate plotted in Figure 4 show, cooperation decreases almost linearly with age in the 20I I survey, whereas in the 2012 survey, cooperation remains stable (and high) until the age of 70 , and then decreases abruptly. Previous research in the United States has found few robust effects of age on cooperation (Groves \& Couper, I998, pp. I35-I36). The lack of robustness is even more marked in cross-national studies (Stoop, Billiet, Koch \& Fitzgerald, 2010, pp. I9-20). According to our data, Switzerland belongs to those countries in which cooperation is lower among older age-groups.

The two variables measuring political participation (past voting record and current vote) show similar effects on both contact and cooperation. The effect of past voting record has a significantly positive effect in all models and in both surveys. Current vote has a significantly positive impact on both contact

\footnotetext{
${ }^{11}$ To some extent, the possibility to fill the 2012 survey online has also contributed to that stability. Online participants are on average about 8 years younger than CATI participants, which increases contact rates especially for people around 30-40 years. However, the patterns concerning age still differ between both surveys when excluding online participants in 2012 (results not shown).
} 
Figure 4

Predicted probability of cooperation by age
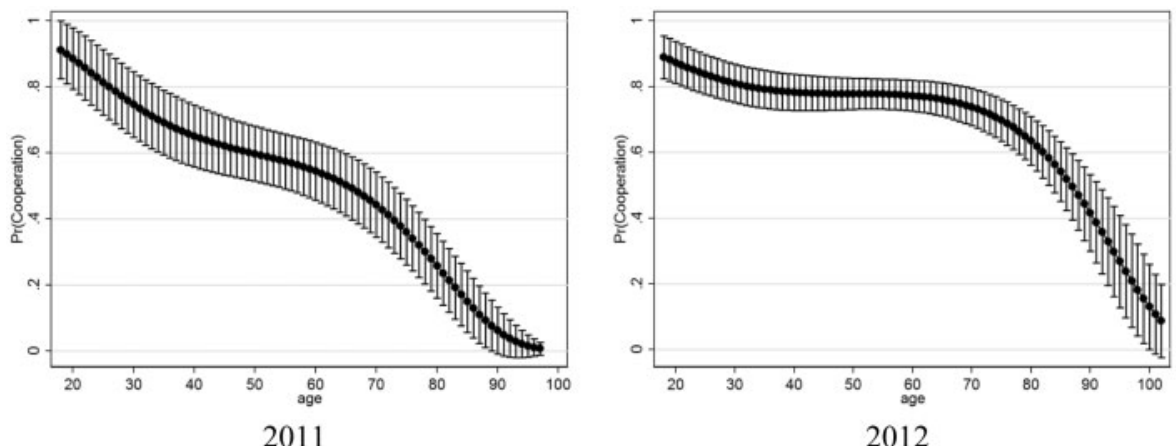

and cooperation in the 2012 survey, but not in the 20 I I survey. However, the effects again get significant once we exclude the past voting record variable from the model in $20 \mathrm{I}$. In sum, both citizens who vote frequently and citizens who participated in the current vote have a higher likelihood to be contacted and to cooperate.

Next, we turn to variables whose effects differ between the contact and cooperation stages. Starting with gender, we can see from Table 2, Model 2 that in both surveys women have a higher probability of being contacted than men. However, in 20I I, this effect is counter-balanced by the lower likelihood of women to cooperate (Model 3). Although the latter effect is not significant, it nevertheless accounts for the absence of a gender effect on survey participation in 20I I (Model I).

Similarly, when discussing the survey participation model, we did not pay too much attention to the effect of residence duration, which is not significant in both surveys. Looking at the contact and cooperation model shows that this variable in fact matters, but its effects work at cross-purpose in the two survey stages. More concretely, long-term residents have a higher likelihood of being contacted, but they have a lower-albeit not significant-propensity to cooperate, which ultimately leads to the nonsignificant impact of residence duration on survey participation.

Finally, in the survey participation model, the coefficients of married persons are significant and positive in both surveys, which at first glance suggests that similar mechanisms are at work. On closer inspection, however, the overrepresentation of married people among survey respondents has different causes in the two surveys. It stems mainly from a higher contact probability in the 20I I survey, and from a higher cooperation probability in the 2012 survey.

Summing up, based on our data we can be fairly confident that especially age, citizens' usual voting propensity, and-to a lesser extent-participation in 
the vote of interest are important and consistent determinants of survey participation and its constitutive components contact and cooperation. Other factors such as sex or marriage, by contrast, are more sensitive to survey characteristics and related response rates. However, having only information about the final outcome - survey participation — and not about the contact and cooperation stages leading to that outcome can hide some of the effects induced by different response rates. For example, the stronger effort made in the 2012 survey to contact sampled citizens has arguably helped to lower the overrepresentation of married people among survey respondents.

In Tables $\mathrm{A}_{4}$ and $\mathrm{A}_{5}$, we break down the analysis further to the two main sources of noncontact and noncooperation, respectively. On the one hand, we run a model that contrasts people who could be contacted, from people for whom we could not find any phone number and from people who could not be reached. On the other hand, we run a model contrasting persons who cooperated to persons who did not for reasons of inability or unwillingness. Age again stands out as a relevant predictor. First, the results regarding the sources of no contact (Table $A_{4}$ ) show that age is a more significant determinant for the "no phone" problem than for reaching the sampled persons (especially in 20II). The "no phone" problem concerns mainly people aged 30-40 years (the so-called "mobile generation" with no fixed landline or unknown mobile number) and very old people, who are likely to be in homes for the aged. The nonavailability of a (fixed) phone may thus also be the main driver of the contact pattern found in Figure 3. Second, the analysis of the sources of no cooperation (Table $A_{5}$ ) reveals that both ability and willingness to cooperate are much lower among oldest citizens.

Tables $A_{4}$ and $A_{5}$ also help to explain the found patterns for residence duration from Table 2. The higher contact rate among long-term residents stems mainly from the high distribution of fixed landlines (see negative effect for "no phone" in Table A4), and the lower cooperation rate from a higher unwillingness to cooperate (see the positive coefficient in Table $A_{5}$, though only significant in 2012). These two results are perhaps linked together: longterm residents may get bothered by the repeated calls of survey companies.

\section{Conclusion}

The question whether turnout bias is primarily a function of measurement error or of nonresponse bias is debated in the literature. According to a widespread view, overreporting contributes to a greater extent to the overestimation of turnout than voter overrepresentation. Some scholars disagree and argue that turnout bias is primarily a function of voter overrepresentation in surveys about politics. While these contrasting views may be owing to differences in survey characteristics, our data contributes to this debate by 
providing highly reliable information about the validated vote of both citizens who were interviewed and citizens who were not. In both surveys, the nonresponse bias associated with the overrepresentation of voters among survey respondents is sizeable. It accounts for almost two thirds of the total turnout bias.

The size of nonresponse bias is especially large in the survey with a lower response rate. Although according to survey research, lower response rate is not necessarily conducive to higher nonresponse bias, our results suggest that there may be such a link in postelection surveys. Further, our results do not confirm that efforts to increase the response rate increase the size of measurement error by bringing more embarrassed nonvoters into the sample. In relative terms, the share of vote overreporting is in fact lower in the survey with the higher response rate.

Taking advantage of the richness of our data, we could conduct an indepth analysis of individual determinants of survey participation and related components (contact and cooperation). This has enabled us to identify at which stage of the survey process nonresponse operates, and to distinguish factors whose effects reinforce each other in both stages, from factors whose effects work at cross-purpose. Age belongs to the first group of factors, as itnonmonotonically-influences survey participation through both contact and cooperation. Similarly, our analysis confirms that voting and responding to a survey about politics go hand in hand. Both contact and cooperation are higher among frequent voters and-to a lesser extent-persons who participated in the vote of interest. Conversely, the higher likelihood of contact among long-term residents and their lower cooperation propensity cancel each other out.

Our findings have broader implications. First, the result that turnout bias is primarily a matter of nonresponse bias alerts us about the importance of studying the bias induced by voter overrepresentation. While the bulk of the existing vote validation literature has focused on overreporting, our results call for a more thorough consideration of how sample selection affects the analysis of turnout bias. Second, our study tends to highlight the virtuous effects of a higher response rate in postelection surveys. The higher contact and cooperation rates achieved in the 2012 survey have led to a lower nonresponse bias, without increasing the measurement bias. Third, survey practitioners may find some useful information in both our general results regarding survey participation and our more specific results regarding contact and cooperation. For instance, the possibility to respond online may help to bring in more of the socalled "mobile generation" with unknown phone numbers.

Of course, our results-especially those regarding the differences in response rate-must be taken with a grain of salt because they are based on two surveys only. More generally, given the sensitiveness of the size and forms of 
turnout bias on differences in survey characteristics and institutional contexts, a study like ours has limitations in terms of external validity and generalizability. We nevertheless hope that our results will motivate other researchers to take into account the nonresponse bias and constitutive elements in future analysis of turnout bias, and this ideally in both the United States and other contexts to widen the scholarly debate.

\section{Acknowledgments}

Earlier versions of this article were presented at the conference of the Swiss Political Science Association 2014 in Bern and at the meeting of Austrian, German and Swiss electoral studies 20I4 in Geneva. We wish to thank the participants and particularly Nicolas Pekari for their helpful comments. We also thank the three anonymous reviewers for their constructive critique. Both authors contributed equally to this work.

Table A

Most Common Reasons and Recoding for Nonparticipation in the Survey

\begin{tabular}{lll}
\hline Noncontact & $\begin{array}{l}\text { No phone } \\
\text { Not reached }\end{array}$ & $\begin{array}{l}\text { No or invalid phone number } \\
\text { Returned letter, answering machine, no answer, } \\
\text { target person (tp) no longer lives in household, } \\
\text { tp went abroad, tp inaccessible during survey } \\
\text { period (e.g., in holidays), appointment scheduled } \\
\text { Age or health problem, language problem, tp died, } \\
\text { lives in home for the elderly, tp overwhelmed }\end{array}$ \\
Noncooperation & $\begin{array}{c}\text { Inability } \\
\text { Unwillingness }\end{array}$ \\
& $\begin{array}{l}\text { Tpefused, against/not interested in surveys, no } \\
\text { time, not interested in topic }\end{array}$
\end{tabular}

Note. The table presents only the most common mentioned reasons that prevented a successful interview. The original data sets comprise even more specific reasons. 
Table A2

Total Turnout Bias, Nonresponse Bias, and Measurement Error According to Survey Mode in 2012

\begin{tabular}{|c|c|c|c|c|c|c|}
\hline \multirow{2}{*}{$\begin{array}{l}\text { Survey } \\
\text { method }\end{array}$} & \multirow{2}{*}{$\begin{array}{l}\text { Validated } \\
\text { turnout in } \\
\text { the initial } \\
\text { sample } \\
\quad(\%)\end{array}$} & \multirow{2}{*}{$\begin{array}{l}\text { Validated } \\
\text { turnout } \\
\text { among } \\
\text { respondents } \\
\quad(\%)\end{array}$} & \multirow{2}{*}{$\begin{array}{l}\text { Reported } \\
\text { turnout } \\
\text { among } \\
\text { respondents } \\
\qquad \%)\end{array}$} & \multirow{2}{*}{$\begin{array}{l}\text { Total } \\
\text { turnout } \\
\text { bias } \\
(\%)\end{array}$} & \multicolumn{2}{|c|}{ Bias estimates } \\
\hline & & & & & $\begin{array}{c}\text { Nonresponse } \\
(\%)\end{array}$ & $\begin{array}{c}\text { Measurement } \\
(\%)\end{array}$ \\
\hline $\begin{array}{l}\text { CATI (n) } \\
\text { online (n) }\end{array}$ & $33 \cdot 4(2,486)$ & $\begin{array}{l}45 \cdot 2(\mathrm{I}, 059) \\
44 \cdot 3(\mathrm{I} 58)\end{array}$ & $\begin{array}{l}53.5(\mathrm{I}, 059) \\
48 . \mathrm{I}(\mathrm{I} 58)\end{array}$ & $\begin{array}{l}20 . \mathrm{I} \\
\mathrm{I} 4.7\end{array}$ & $\begin{array}{l}\text { I I } .8 \\
\text { I } 0.9\end{array}$ & $\begin{array}{l}8.3 \\
3.8\end{array}$ \\
\hline
\end{tabular}

Note. This table excludes the I4 respondents who did not answer the turnout question.

Table $\mathrm{A}_{3}$

Nonresponse Bias and Measurement Error According to the Timing of the Interviem

\begin{tabular}{|c|c|c|c|c|c|c|}
\hline \multirow[t]{2}{*}{ Year } & \multirow{2}{*}{$\begin{array}{l}\text { Validated } \\
\text { turnout in } \\
\text { the initial } \\
\text { sample } \\
\qquad(\%)\end{array}$} & \multirow{2}{*}{$\begin{array}{l}\text { Timing of } \\
\text { the } \\
\text { interview }\end{array}$} & \multirow{2}{*}{$\begin{array}{l}\text { Validated } \\
\text { turnout } \\
\text { among } \\
\text { respondents } \\
\quad(\%)\end{array}$} & \multirow{2}{*}{$\begin{array}{l}\text { Reported } \\
\text { turnout } \\
\text { among } \\
\text { respondents } \\
\quad(\%)\end{array}$} & \multicolumn{2}{|c|}{ Bias estimates } \\
\hline & & & & & $\begin{array}{c}\text { Nonresponse } \\
(\%)\end{array}$ & $\begin{array}{c}\text { Measurement } \\
(\%)\end{array}$ \\
\hline \multirow{3}{*}{20 I I } & \multirow{3}{*}{46.8} & First week & $7 \mathrm{I} .4$ & 77.4 & 24.6 & 6.0 \\
\hline & & Second week & 52.7 & 62.5 & $5 \cdot 9$ & 9.8 \\
\hline & & Third week & 48.8 & 60.0 & 2.0 & I I .2 \\
\hline \multirow{3}{*}{2012} & \multirow{3}{*}{$33 \cdot 4$} & First week & 49.8 & $57 \cdot \mathrm{I}$ & I6.4 & $7 \cdot 3$ \\
\hline & & Second week & 38.0 & 46.5 & 4.6 & 8.5 \\
\hline & & Third week & 38.2 & 46.6 & 4.8 & 8.4 \\
\hline
\end{tabular}

Note. This table excludes respondents who did not answer the turnout question (one person in 20 I I and I4 persons in 2012). 
INTERNATIONAL JOURNAL OF PUBLIC OPINION RESEARCH

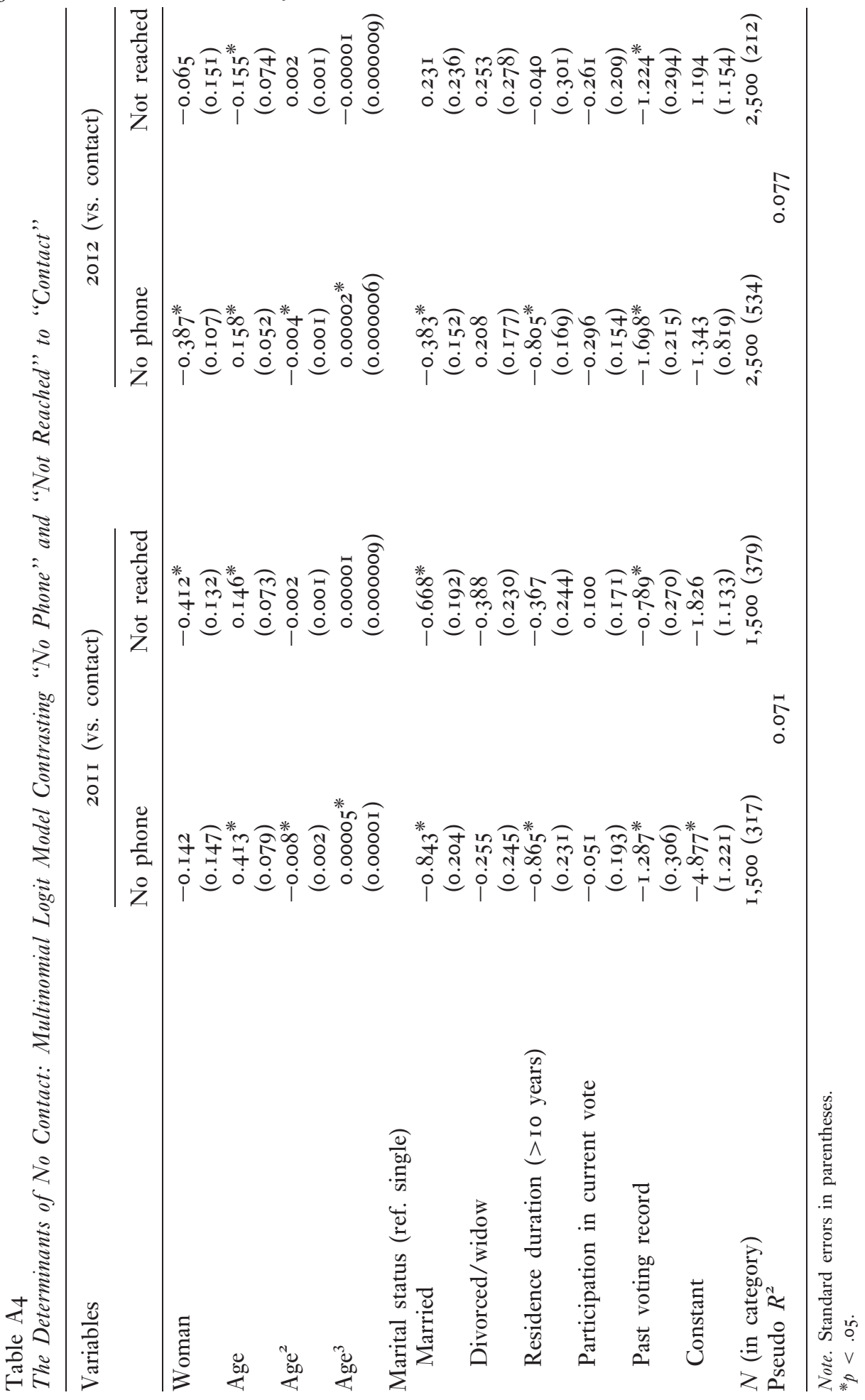




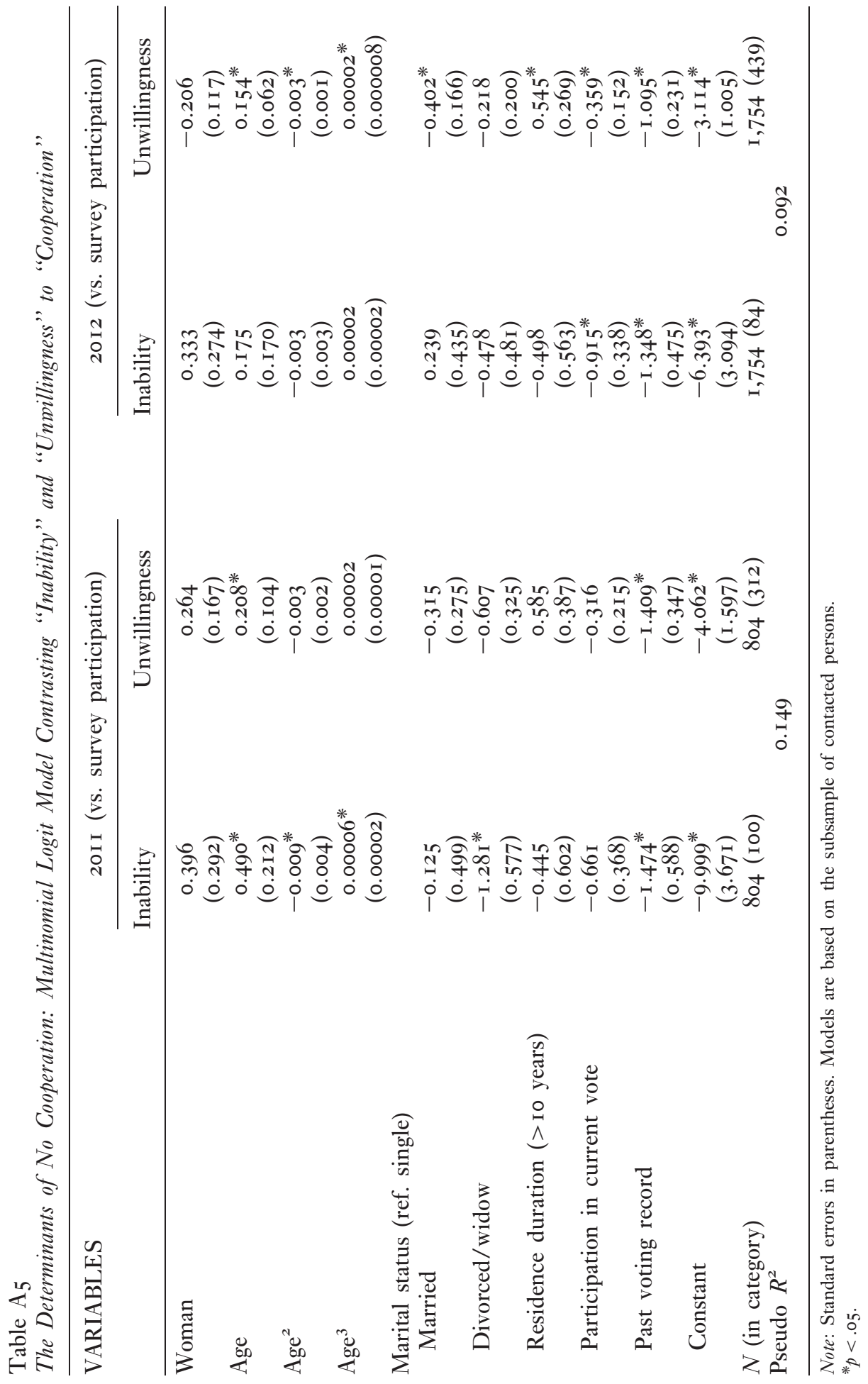




\section{References}

Ansolabehere, S., \& Hersh, E. (2012). Validation: What big data reveal about survey misreporting and the real electorate. Political Analysis, 20, 437-459.

Ansolabehere, S., Hersh, E., \& Shepsle. K. (20I2). Movers, stayers, and registration: Why age is correlated with registration in the U.S. Quarterly Fournal of Political Science, 7, 333-363.

Atkeson, L. R., Adams, A. N., \& Alvarez, R. M. (20I4). Nonresponse and mode effects in self- and interviewer-administered surveys. Political Analysis, 22, 304-320.

Belli, R. F., Traugott, M. W., \& Beckman, M N. (200I). What leads to voting overreports? Contrasts of overreporters to validated voters and admitted nonvoters in the American National Election Studies. Fournal of Official Statistics, I7, 479-498.

Berent, M. K., Krosnick, J. A., \& Lupia. A. (201 I). The quality of government records and "over-estimation" of registration and turnout in Surveys: Lessons from the 2008 ANES Panel Study's Registration and Turnout Validation Exercises. Ann Arbor, MI; Palo Alto, CA: American National Election Studies. Working paper nesor 2554, Retrieved from: http://www.electionstudies.org/resources/papers/ nesor2554.pdf

Bernstein, R., Chadha, A., \& Montjoy, R. (200I). Overreporting voting: Why it happens and why it matters. Public Opinion Quarterly, 65, 22-44.

Bochsler, D., \& Wasserfallen, F. (20I3). Switzerland: Moving towards a nationalized party system. In R. Dandoy \& A. H. Schakel (Eds.), Regional and national elections in Western Europe - Territoriality of the vote in thirteen countries (pp. 234-253). Houndmills: Palgrave.

Brehm, J. (I993). The phantom respondents. Opinion surveys and political representation. Ann Arbor, MI: University of Michigan Press.

Burden, B. C. (2000). Voter turnout and the National Election Studies. Political Analysis, 8, 389-398.

Cassel, C. A. (2003). Overreporting and electoral participation research. American Politics Research, 3I, 8I-92.

Cassel, C. A., \& Hill, D. B. (I98I). Explanations of turnout decline: A multivariate test. American Politics Research, 9, I8I-I95.

Chang, L., \& Krosnick, J. A. (2009). National surveys via RDD telephone interviewing versus the internet: Comparing sample representativeness and response quality. Public Opinion Quarterly, 73, 64I-678.

Curtin, R., Presser, S., \& Singer, E. (2000). The effects of response rate changes on the index of consumer sentiment. Public Opinion Quarterly, 64, 4I3-428.

De Leeuw, E., \& de Heer, W. (2002). Trends in household survey nonresponse: A longitudinal and international comparison. In R. Groves, D. A. Dillman, J. L. Eltinge, \& R. J. A. Little (Eds.), Survey nonresponse (pp. 4I-54). New York, NY: Wiley.

Deufel, B. J., \& Kedar, O. (2010). Race turnout in U.S. Elections: Exposing Hidden Effects. Public Opinion Quarterly, 74, 286-3 I8.

Franklin, M. (2004). Voter turnout and the dynamics of electoral competition in established democracies since I945. Cambridge: Cambridge University Press. 
Galesic, M., \& Bosnjak, M. (2009). Effects of questionnaire length on participation and indicators of response quality in a web survey. Public Opinion Quarterly, 73, $349-360$.

Goyder, J. (I987). The silent minority. Nonrespondents on sample surveys. Boulder, CO: Westview Press.

Groves, R. M. (2006). Nonresponse rates and nonresponse bias in household surveys. Public Opinion Quarterly, 70, 646-675.

Groves, R. M., \& Mathiowetz, N. (I984). Computer assisted telephone interviewing: Effects on interviewers and respondents. Public Opinion Quarterly, 48, 356-369.

Groves, R. M., Cialdini, R. B., \& Couper, M. P. (I992). Understanding the decision to participate in a survey. Public Opinion Quarterly, 56, 475-495.

Groves, R. M., \& Couper, M P. (I998). Nonresponse in household interviem surveys. New York, NY: Wiley.

Groves, R. M., Singer, E., \& Corning, A. (2000). Leverage-saliency theory of survey participation: Description and an illustration. Public Opinion Quarterly, 64, 299-308.

Groves, R. M., Presser, S., \& Dipko, S. (2004). The role of topic interest in survey participation decisions. Public Opinion Quarterly, 68, 2-3 I.

Groves, R. M., \& Peytcheva, E. (2008). The impact of nonresponse rates on nonresponse bias. Public Opinion Quarterly, 72, I67-189.

Katz, J. N., \& Katz, G. (2010). Correcting for survey misreports using auxiliary information with an application to estimating turnout. American fournal of Political Science, 54, 8I $5-835$.

Lin, I.-F., \& Schaeffer, N. (I995). Using survey participants to estimate the impact of nonparticipation. Public Opinion Quarterly, 59, 236-258.

Lutz, G., \& Selb, P. (2007). The national elections in Switzerland. In U. Klöti, P. Knoepfel, H. Kriesi, Y. Papadopoulos, \& P. Sciarini (Eds.), Handbook of Smiss politics (pp. 405-434). Zürich: NZZ Libro.

Marcus, B., Bosnjak, M., Lindner, S., Pilischenko, S., \& Schuetz, A. (2007). Compensating for low topic interest and long surveys: A field experiment on nonresponse in web surveys. Social Science Computer Reviem, 25, 372-383.

McDonald, M. P. (2003). On the overreport bias of the National Election Study turnout rate. Political Analysis, II, I80-186.

Olson, K. (2006). Survey participation, nonresponse bias, measurement error bias, and total bias. Public Opinion Quarterly, 70, 737-758.

Presser, S., \& Traugott, M. W. (I992). Little white lies and social science models: Correlated response errors in a panel study of voting. Public Opinion Quarterly, 56, $77-86$.

Quinn, R. P., Gutek, B. A., \& Walsh, J. T. (I980). Telephone interviewing: A reappraisal and a field experiment. Basic and Applied Social Psychology, 2, I27-153.

Roberts, C., Eva, G., Allum, N., \& Lynn, P. (2010). Data quality in telephone surveys and the effect of questionnaire length: A cross-national experiment. Institute for Social and Economic Research Working Paper 2010-36. Colchester, UK: University of Essex, retrieved from https://www.iser.essex.ac.uk/publications/working-papers/ iser/2010-36

Riley, M. W., Foner, A., \& Waring, J. (ı988). Sociology of age. In N. J. Smelser (Ed.), Handbook of sociology (pp. 236-277). Newbury Park, CA: Sage. 
Sciarini, P., Cappelletti, F., Goldberg, A. C., \& Lanz, S. (forthcoming). The underexplored species: Selective participation in direct democratic votes. Smiss Political Science Reviem. Early view. doi: го. I I I/spsr. г2 I 78 .

Sciarini, P., \& Goldberg, A. C. (forthcoming). Turnout bias in postelection surveys: Political involvement, survey participation and vote overreporting. Fournal of Survey Statistics and Methodology.

Selb, P., \& Munzert, S. (2013). Voter overrepresentation, vote misreporting, and turnout bias in postelection surveys. Electoral Studies, 32, I86-196.

Sigelman, L. (1982). The nonvoting voter in voting research. American fournal of Political Science, 26, 47-56.

Silver, B. D., Anderson, B. A., \& Abramson, P. R. (I986). Who overreports voting? The American Political Science Reviem, 80, 613-624

Smith, T. W. (I983). The hidden 25 percent: An analysis of nonresponse on the I980 general social survey. Public Opinion Quarterly, 47, 386-404.

Squire, P., Wolfinger, R. E., \& Glass, D. P. (I987). Residential mobility and voter turnout. The American Political Science Reviem, 8I, 45-66.

Stoop, I. (2005). The hunt for the last respondent. Nonresponse in sample surveys. The Hague: SCP, Social and Cultural Planning Office of the Netherlands.

Stoop, I., Billiet, J., Koch, A., \& Fitzgerald, R. (2010). Improving survey response: Lessons learned from the European Social Survey. London: Wiley.

Tawfik, A., Sciarini, P., \& Horber, H. (20I2). Putting voter turnout in a longitudinal and contextual perspective: An analysis of actual participation data. International Political Science Reviem, 33, 352-37I.

Tourangeau, R., \& Yan, T. (2007). Sensitive questions in survey. Psychological Bulletin, I33, 859-883.

Tourangeau, R., Groves, R. M., \& Redline, C. D. (2010). Sensitive topics and reluctant respondents: Demonstrating a link between nonresponse bias and measurement error. Public Opinion Quarterly, 74, 4I3-432.

Voogt, R. J. J., \& Saris, W. E. (2005). Mixed mode designs: Finding the balance between nonresponse bias and mode effects. Fournal of Official Statistics, 2I, $367-387$.

Yaeger, D. S., Krosnick, J. A., Chang, L., Javitz, H. S., Levendusky, M. S., Simpser, A., \& \& Wang, R. (20II). Comparing the accuracy of RDD telephone surveys and internet conducted with probability and non-probability samples. Public Opinion Quarterly, 75, 709-747.

\section{Biographical Notes}

Pascal Sciarini is Professor of Swiss politics at the University of Geneva. His main research topics are political decision-making processes, direct democracy, and political behavior (elections and referendums). He has published in several journals, such as European Journal of Political Research, Electoral Studies, European Political Science Review, International Journal of Public Opinion Research, Journal of Legislative Studies, and West European politics. He has co-authored Political decision-making in Smitzerland: The consensus model under pressure Basingstoke/New York: Palgrave Macmillan, 20I5. 
Andreas Goldberg is teaching and research postdoc at the University of Geneva. He is also a collaborator of the Swiss Election Studies (SELECTS) at FORS, Lausanne. His research focuses on electoral behavior, particularly linked to cleavages, voter turnout, and context effects. Other fields of interest include survey research (turnout bias and misreporting) and e-voting. 